\title{
1D and 0D Advantage Materials Application on TCO Surface On Dye Sensitized Solar Cells
}

\author{
[ Halil İbrahim YAVUZ ${ }^{1}$ ]
}

\begin{abstract}
Semiconductor metal oxide nanowires (SCMONWs) are favorable materials for various quantum devices which have one dimensional interaction and huge surface-to-volume ratio. Growth of these nanowires is commonly performed using expensive techniques requiring high vacuum and high temperature conditions, which also consume some hazardous raw materials. However, the sol-gel technique employed in this study is used primarily for the fabrication of materials including metal oxides beginning from a wet chemical solution, where low temperatures and non-vacuum conditions are utilized. Indium tin oxide (ITO) is generally used as a transparent conducting oxide for solar cells and LCD, touch screens applications. In this work, indium tin oxide (ITO) nanoparticles, nanowires and thin films are prepared on glass substrates by solgel technique and used for the production of nano-crystalline dye-sensitized solar cells (nc-DSSC), which are a relatively new class of low-cost thin film solar cells. Structural, topographical and chemical analyses were performed using XRD, SEM and EDS. SEM analysis confirm the presence of $15 \mathrm{~nm}$ thick and 500 $\mathrm{nm}$ long nanowires obtained $24 \mathrm{~h}$ treatment ITO. The transparency of the ITO films is analyzed using UV spectrometer. 24h treatment of ITO nanowires in nc-DSSCs causes an improvement of $83 \%$ in the power converted efficiency and $30 \%$ indecent photo current efficiency with respect to pure $\mathrm{TiO}_{2}$ based dye sensitized solar cells
\end{abstract}

Keywords-Solar cells, Dye sensitized solar cell, Advantage materials, nanotechnology, nanomaterials, energy

\section{Introduction}

After the introduction in 1991, dye-sensitized solar cells (DSSC) have attracted great interest due to their large potential applications as a cheap alternative candidate to replace conventional silicon-based $\mathrm{p}-\mathrm{n}$ junction solar cells. The key points of highly efficient dye sensitized solar cell production depends on light harvesting, charge generation and charge transport in photoelectode components. The photoelectrode is composed of a photogenarator nanoporous oxide thick film and a highly transparent conducting oxide (TCO) thin film. Most of research has been reported about working principle, problems and solution on photovoltaic generation on DSSCs. Nevertheless, important parameters of light conversion efficiency which are light transmittance, charge collection, and charge extraction to the external circuit take place on TCO, it has been barely researched. A lot of widely used transparent conductor and commercially TCOs has been used of DSSC applications such as FTO (F:SnO2), ITO (In:SnO2), ATO (Sn:SbO2), and AZO (Al:ZnO).

Indium tin oxide (ITO, tin-doped indium oxide) is a nanocomposite solid-solution of $\mathrm{In} 2 \mathrm{O} 3$ and $\mathrm{SnO} 2$ in 10:1 ratio. ITO which is an advanced ceramic material can be applied to numerous optoelectronic devices due to its excellent properties of high conductivity and high transparency and it is colorless to visible light in thin film layers while in bulk form it is yellowish to grey. The high electrical conductivity is originated from Sn dopants which create a conducting carrieroxygen vacancy at the matrix $\left(\operatorname{In}_{2} \mathrm{O}_{3}\right)$.

Although ITO which is barely expensive than other choice, still best performance on highly transparency and lowest resistivity. There are fairly two problems using ITO on DSSC applications. One of them is production cost of ITO can be solved by sol-gel processing which is one of the cheap attractive solution based technique. The second problem is interaction between maximize the interface area between the transparent conductive indium tin oxide (ITO)-coated glass electrode and the photo anodic $\mathrm{TiO} 2$ layer. For this purpose several work has been focused on about the interface area has been developed using 1D nanostructure of ITO nanowires to obtain an electrode with a high interface area. To produce highly efficient the interfacial area between ITO- $\mathrm{TiO}_{2} \mathrm{~h}$, Cross like 1-D nanostructure of ITO is needed. Before this report there is no advantage report presenting in literature. ITO nanowires can be produced using several methods such as laser ablation, electrospinning, electro deposition, and sputtering.

In this work, indium tin oxide (ITO) nanoparticles, nanowires and thin films have been realized on glass substrates by sol-gel technique and these were used for the production of nano-crystalline dye-sensitized solar cells (ncDSSC), which are a relatively new class of low cost thin film solar cells.

ITO film produced by sol-gel method showed enhanced optical characteristics an electrical conductivity after annealing, ITO nanowire modification helps to increase interaction between the interface area between the transparent conductive indium tin oxide (ITO)-coated glass electrode and the photo anodic $\mathrm{TiO}_{2}$ layer, and charge transport properties.

\section{Authors Name ${ }^{1}$}

Department of Mechanical Engineering, Yüzüncü Yıl University, Zeve Campus, 65080

Turkey 


\section{Experimental}

\section{A. Synthesis of ITO gel}

In(NO3)5 (Aldrich Chemical Co.) and $\mathrm{SnCl} 4$ (Aldrich Chemical Co.) were mixed with a solution of ultra-pure water, acetic acid (HA) (Merck Chemical Co.) and polyethylene glycol (PG) in a $250 \mathrm{ml}$ flux at $80{ }^{\circ} \mathrm{C}$. Different solvent concentrations and their effect on the gel formation are shown in figure 1. In the light of the observed data, Increase of water would increase the hydrolysis rate and hence decrease the gel time. On the contrary, when water was in excess, the gel time increased slightly. The water addition adverse effect on reaction rate. As a result $\mathrm{H} 2 \mathrm{O} / \mathrm{PG}=10$ and $\mathrm{PG} / \mathrm{HA}=4$ concentrations were best performance of reaction time, therefore they has been selected for the synthesis of ITO gel.

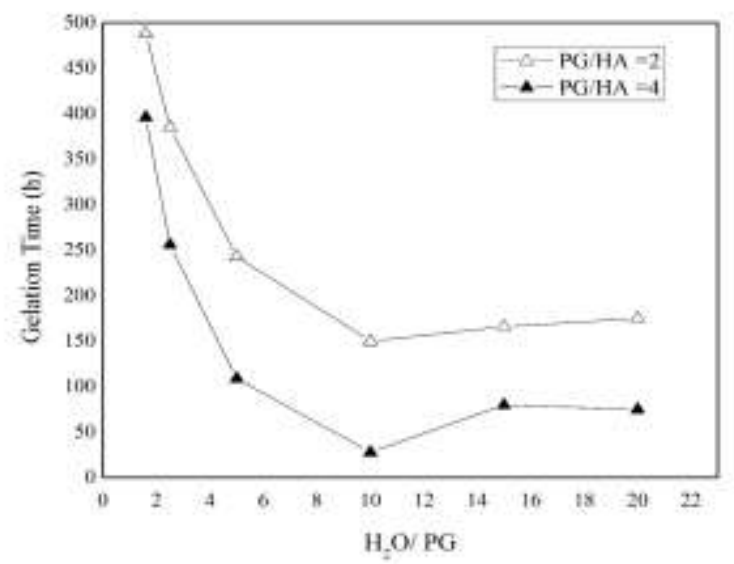

Figure 1. The results for the gel formation as a function of $\mathrm{H} 2 \mathrm{O} / \mathrm{PG}$ for two HA/PG weight ratios.

\section{B. Synthesis of ITO film, nanopowdres, nanowires and $\mathrm{TiO}_{2}$ nanopowders}

The glass substrates were sonicated in distilled water, acetone and isopropanol mixture (1:1:1 volume ratio) for 15 min. Then, they were cleaned in a detergent solution for 10 min, and then dipped in isopropanol-HCN mixture (5:1) for 35 min in an ultrasonic homogenizator. All substrates were rinsed with distilled water and alcohol for three times, and then dried under air flow. The glass surfaces were coated by ITO gel using spin coating technique at $900 \mathrm{rpm} 4 \mathrm{~s}$ and $2750 \mathrm{rpm}$ at $30 \mathrm{sec}$. Following deposition, the ITO films were dried 20- 30 min at $20 \mathrm{oC}$ and annealed at $400 \mathrm{oC}$ for $2 \mathrm{~h}$.

\section{Synthesis of ITO nanopowdres, nanowires and $\mathrm{TiO}_{2}$ nanopowders}

In order to obtained better and faster ITO nanowire, nucleation step is needed. The nucleation step depends on agglomerated nano particles (seed). To produce the suitable seed particles, the gels were dried at $40{ }^{\circ} \mathrm{C}$ for $2 \mathrm{~h}$ and $60{ }^{\circ} \mathrm{C}$ for $2 \mathrm{~h}$ and then annealed at $400{ }^{\circ} \mathrm{C}$ for $2 \mathrm{~h}$ ITO nano powders (ITO pw) were obtained. The Figure 2 represents FE-SEM images of ITO pw which is average particles size 10-20nm.

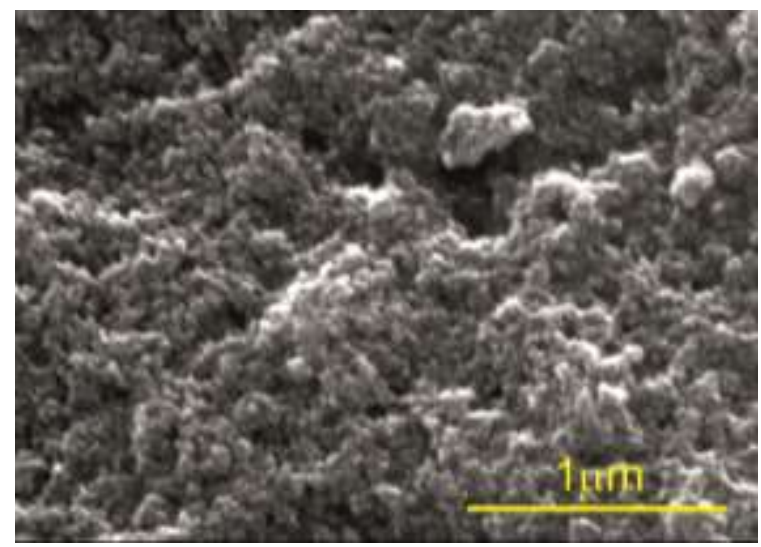

Figure.2 SEM micrograph of ITO nano powders obtained by sol-gel method.

\section{Synthesis of ITO film nanowires}

ITO nanowires (ITO nw) were obtained by seeding ITO nanopowders on ITO thin films and keeping them in a solution of $1 \mathrm{mM}$ 10:1 In(NO3)5 (Aldrich Chemical Co.) and $\mathrm{SnCl} 4$ (Aldrich Chemical Co.) for $24 \mathrm{~h} 12 \mathrm{~h}, 6 \mathrm{~h}$ by two steps as seen in Figure $3 \mathrm{a}$ and Figure $3 \mathrm{~b}$.

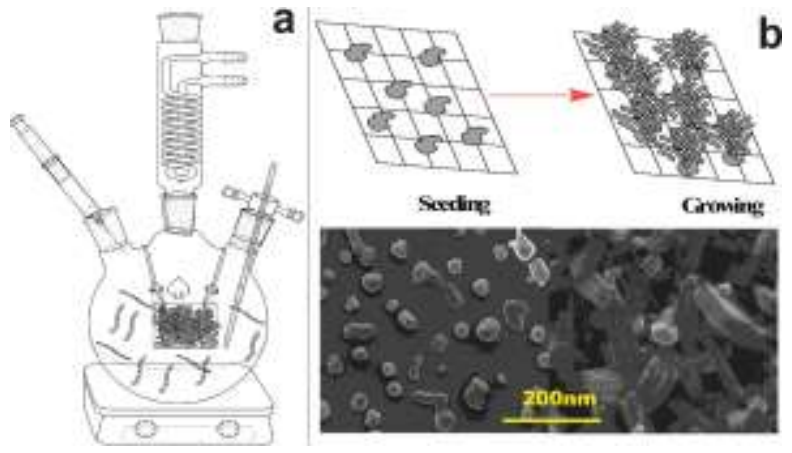

Figure 3. (a) Schematic reaction vessel for the production of ITO nanowires. (b) Schematic of nanowire growth steps.

$150 \mathrm{mg}$ ITO nanopowders and $8 \mathrm{ml}$ ethanol were mixed, crushed, and grinded using an agate mortar. After grinding, mixture was transferred to a Teflon beaker adding some ethanol by completing to volume of $50 \mathrm{ml}$. Then, $0.5 \mathrm{ml}$ HNO3 was added to the solution in order to prevent agglomeration of these particles. Finally, the solution was mixed with a magnetic strip and sonicated with an ultrasonic horn (with cycles of $3 \mathrm{~s}$ work, $3 \mathrm{~s}$ rest). This ITO seeding solution was applied on ITO coated glass substrates by spin coater two times at $2000 \mathrm{rpm}$ and final annealing was done at $400 \mathrm{oC}$ for 30 minutes. Seeding step is crucial for nucleation of ITO nanowire. ITO seeded substrates can be seen in the SEM micrograph of Figure $3 b$. 
The annealed ITO seeded substrates were placed in a reaction vessel perpendicular to the vessel bottom (Figure 1.a). Then $1 \mathrm{mM}$ 10:1 $\mathrm{In}(\mathrm{NO} 3) 5$ and $\mathrm{SnCl} 4$ solution were added until the substrate was completely covered. The nanowires were obtained by hydrothermal treatment in the solution at 85 $\mathrm{oC}$ for $24 \mathrm{~h}$. (Figure 2). The nanowire length and homogeny distribution was found to increase with time of growth step, Figure 2 However, on the negative side, the angle of substrate is most important parameter. Only nanowire formation was obtain sample has in 900 angle to base of reaction weasel. The figure 4.a and 4.b represent to ITO nanowires obtained by hydrothermal treatment at $85 \mathrm{oC}$ for $24 \mathrm{~h}$.

\section{E. Synthesis of $\mathrm{TiO}_{2}$ nanopowders}

$\mathrm{TiO}_{2}$ nano powders were synthesized through a sol-gel method using tetraisopropyl orthotitanate (Aldrich Chemical Co.), isopropanol alcohol, ethylene glycol, polyethylene glycol (monolaurate) and acetic acid (HA) (Aldrich Chemical Co.) [28]. After adding a few droplets of water, a very soft whiteblue colored gel was obtained and this gel was homogenized in two steps. The first step is mechanical homogenization by TiCl4 treated SS316 blender (Daihan homogenizator). The final homogenization is ultrasonic homogenization by a titanium probe (Bandelin Sonoplus HD 2070) using 3 cycles, of $\% 75$ power for $2 \mathrm{~min}$. Then, the gel was dried at $70{ }^{\circ} \mathrm{C}$ in a rotary evaporator at $100 \mathrm{mbar}$. Finally, the glass-like dried gel was transferred to a crucible and annealed at $550{ }^{\circ} \mathrm{C}$ for $2 \mathrm{~h}$ yielding nanoparticles of $\mathrm{TiO}_{2}$. The surface area of $\mathrm{TiO}_{2}$ was determined $64 \mathrm{~m}^{2} / \mathrm{g}$ by The Brunauer-Emmett-Teller (BET) method. The value of BET is higher than commercial P25 (BET $56 \mathrm{~m}^{2} / \mathrm{g}$ ). The higher surface helps to photoanode absorb more dye.

\section{F. Fabrication of the nanocomposite ITO-TiO ${ }_{2}$ dye-sensitized solar cell}

ITO glasses were treated by $\mathrm{TiCl}_{4}$ solution at 30 minutes due to protection of recombination caused liquid electrolyte touch the ITO surface. The dye-sensitized $\mathrm{TiO}_{2}$ electrodes were prepared from the $\mathrm{TiO}_{2}$ paste synthesized by sol-gel method and coated on ITO film and ITO nanowires by Doctor Blade technique. The transparent counter Pt electrode was assembled into a sandwich type cell. The electrolyte, which was prepared from the solution of 10:1:5 lithium iodide, iodide and 4-tert-butylpyridine in acetonitrile, was injected into the interspaces between the photoanode and the counter electrode and the two electrodes were brought together using Surlyn (25 $\mu \mathrm{m})$ frames and laminated at $120{ }^{\circ} \mathrm{C}$. The active cell area was $0.25 \mathrm{~cm} 2$.

\section{Results and Discussion}

\section{A. ITO Films}

To determine best sol-gel based ITO for DSSC applications, different cycle (Times) coated sample has been analyzed. UV/Visible/near IR (UV-NIR) spectra were taken using a Perkin-Elmer Fourier transform Lambda $950 \mathrm{UV} / \mathrm{vis}$ spectrometer over a wavelength range of 330 to $2500 \mathrm{~nm}$ in both transmission $\mathrm{n}$ and reflection modes. The transmission spectra background was taken against an air background and substrate absorbance. UV-NIR transparency spectra analyses (figure 4.a.) of different cycle (times) ITO coated glass substrates were carried out, which indicates that the transparency of 5 Cycle times ITO (5T) coated glass substrates has showed best performance. The transparency of 5T between $330-1000 \mathrm{~nm}$ was average $80 \%$ and $\sim 85 \%$ transmission at $550 \mathrm{~nm}$. Due to ITO direct band gap started to absorb bellow the $400 \mathrm{~nm}$ wavelength, the transmission falls rapidly. Transmission approaches zero while wavelength close the $330 \mathrm{~nm}$. Included in Figures $4 . \mathrm{b}$ is plot of reflectivity spectra, the $3 \mathrm{~T}$ film also showed $\sim 33 \%$ reflectivity in the infrared at $2500 \mathrm{~nm}$ in air. The transparency for 3T and $10 \mathrm{~T}$ decreased slightly to $\sim 70 \%$ and $\sim 60 \%$. The sheet resistance analyses of ITO thin films, which were carried out on Keithley analyzer system using a mercury probe, are given in Table 1.

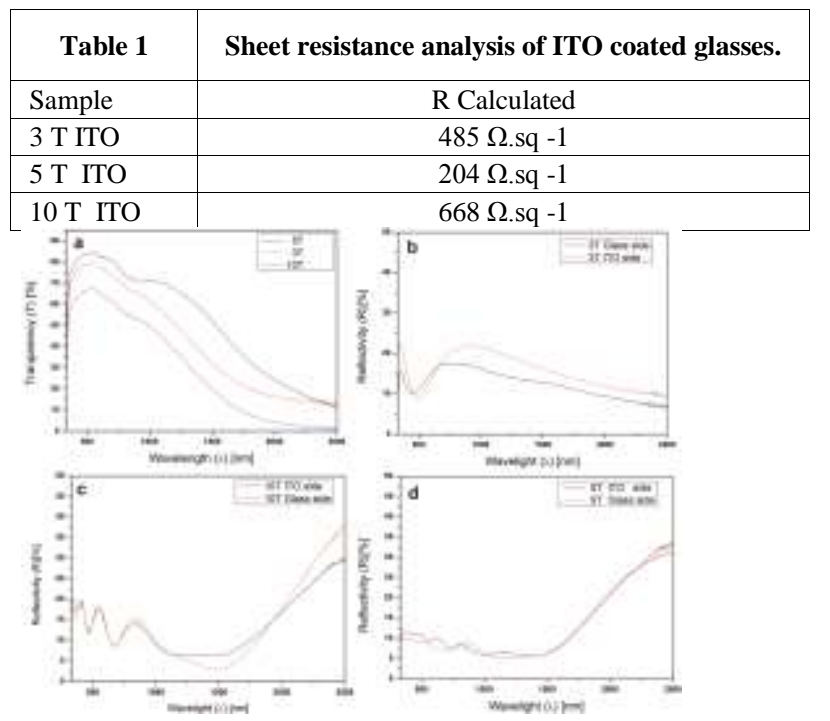

Figure 4. (a). Transmittance analysis of 3 times ITO coated (3T), 5 times ITO coated (5T), and 10 times ITO coated (10T) glass substrates. Reflectivity analysis of 3T (b), $5 \mathrm{~T}$ (c) and 10T (d).

The band gap of the ITO films can be calculated from the transmission data in the lower wavelength region. By extrapolating the linear portion of the $(\alpha h v) 2$ vs photon energy (E(ev) graph gives the direct band gap of the sample.
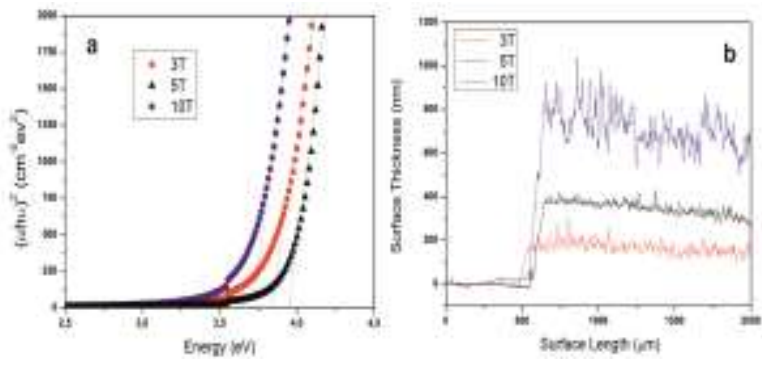

Figure 5.a. linear portion of the $(\alpha \mathrm{hv}) 2$ vs photon energy $\mathrm{E}(\mathrm{ev})$ graph of $3 \mathrm{~T}, 5 \mathrm{~T}$ and 10T ITO coated glass substrates. b. 
surface profilometer results of 3T, 5T and 10T ITO coated glass substrates.

Figure 5.a. is the plot of $(\mathrm{hv} \alpha) 2$ vs photon energy $(\mathrm{E}(\mathrm{ev})$ from which the direct optical band gap is calculated. The optical band gap (E,) for $300 \mathrm{~nm}$ ITO film is $3.94 \mathrm{eV}$. The results of 5T of Egap close the literature (\%10 tin doped In2O5 thin film $3.93 \mathrm{eV}$, which was produced by spatter). But on the $3 \mathrm{~T}$ and $10 \mathrm{~T} 3,80 \mathrm{eV}$ and $3,70 \mathrm{eV}$ direct band gap, it was higher the literature. Therefore 5T sample was used as transparent conductive glass on DSSC application, on fallowing experiments which is illustrated DSSCs continue whit 5T samples. After decide the 5T sample used as a transparent conductive glass on DSSC application.A computer-controlled Keithley 2400 source meter with 300 W AM 1.5 simulated sunlight ( $2 \mathrm{X} 2$ beam, w/6258 lamp) was employed to obtain the current density-voltage (J-V) characteristics. The active areas of all of the ITO-TiO 2 DSSCs were $0.25 \mathrm{~cm} 2$. The results of the current density-voltage (J$\mathrm{V})$ curves are given below in Table 4 and $\mathrm{J}-\mathrm{V}$ characteristic curves are shown in Figure 8.

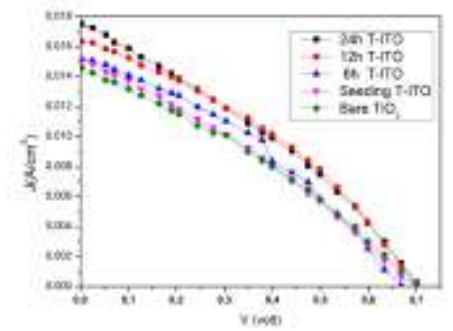

Figure 6. Current density-voltage characteristics of ITO nanowire and $\mathrm{TiO}_{2}$ nano powder composite dye sensitized solar cells.

On the table 2 shows that short circuit current density, Jsc increases with ITO treatment time increases, due to improvement in contact surface of ITO- $\mathrm{TiO}_{2}$. The best improvement is found $175 \mathrm{~mA}$ in $24 \mathrm{~h}$ T-ITO. Seeding of ITO and $6 \mathrm{~h}$ T-ITO has nearly same Jsc. After ITO nanowires treatment under before coated $\mathrm{TiO}_{2}$ matrix, ITO nanowires help the electrons to reach to the electrode surfaces causing an increase in the efficiency. That is why we observe higher efficiency than pure $\mathrm{TiO}_{2}$ structures. There is not much differences between 24 and 48 hours treatment. Therefore 24 hours ITO nanowire treatment enough to get higher efficiency on the $\mathrm{TiO}_{2}$ matrix, during the production of DSSC doctor blade technique. ITO nanowires reach the maximum effect on the photovoltaic conversation on ITO substrate after 24 hours treatment.

\begin{tabular}{|c|c|c|c|c|}
\hline Table 2 & \multicolumn{4}{|c|}{$\begin{array}{c}\text { Efficiency analysis of ITO nanowire and } \mathrm{TiO}_{2} \\
\text { nano powder composite dye sensitized solar cells. }\end{array}$} \\
\hline Sample & $\begin{array}{c}\text { Fill } \\
\text { Factor } \\
(\%)\end{array}$ & $\begin{array}{c}\mathbf{J}_{\mathrm{sc}} \\
\left(\mathrm{mA} / \mathrm{cm}^{2}\right)\end{array}$ & $\begin{array}{c}\mathrm{V}_{\text {oc }} \\
(\text { Volt })\end{array}$ & $\begin{array}{c}\text { Efficiency } \\
(\%)\end{array}$ \\
\hline 24 T-ITO & 40.46 & 17,50 & 0,710 & 3.26 \\
\hline 12 T-ITO & 39.21 & 16.25 & 0,705 & 3.21 \\
\hline
\end{tabular}

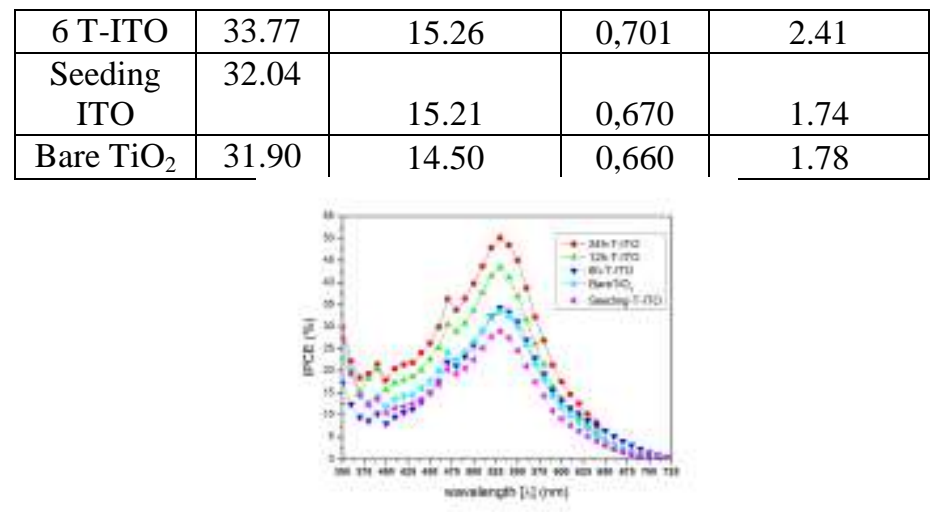

Figure 7. IPCE spectra of DSSCs based on $\mathrm{Bare}^{\mathrm{TiO}}{ }_{2}$ and 24 h T-ITO sample.

On The IPCE curve (figure7), the photosensitization of the $\mathrm{TiO}_{2}$ electrodes in the visible region is clearly observed. 540 $\mathrm{nm}$ peak is much higher than $460 \mathrm{~nm}$ therefore, $540 \mathrm{~nm}$ peak is more effect in light absorption around $540 \mathrm{~nm}$. There are no differences between $6 \mathrm{~h}$ T-ITO and bare $\mathrm{TiO}_{2}$. It is due to the light absorption of the ITO when the light is incident from the ITO substrates. However \%59 improvement has been observed total IPCE.

EIS technique has been widely employed to investigate the kinetics of electrochemical and photo electrochemical process occurring in DSSCs, super capacitor and lithium cell. The impedance spectra of 24h T-ITO, 6h T-ITO and Bare $\mathrm{TiO}_{2}$ synthesis by sol-gel method were given figure 9. The experiments were under illumination whit ranging from $0.1 \mathrm{~Hz}$ ro $100 \mathrm{kHz}$ at Voc with values $710 \mathrm{mV}$ for $24 \mathrm{~h}$ ITO and 715 $\mathrm{mV}$ for $12 \mathrm{hT}$-ITO and $701 \mathrm{mV}$ for $6 \mathrm{~h}$ T-ITO $670 \mathrm{mV}$ for seeding ITO and $660 \mathrm{mV}$ for $\mathrm{Bare}^{\mathrm{TiO}_{2}}$. On the Nyquist plots of EIS spectra, two semicircles were observed. On the light of resources on the EIS model analysis in the DSSC, values of important EIS parameters (Rct and Rw) were calculated by Zsimpwin software. The calculated EIS data given in table 3 .

\begin{tabular}{|c|c|c|c|c|c|c|}
\hline Table 3 & \multicolumn{7}{|c|}{ The calculated EIS data } \\
\hline Samples & $\begin{array}{c}\text { Rs } \\
(\boldsymbol{\Omega})\end{array}$ & $\begin{array}{c}\text { Rct } \\
(\boldsymbol{\Omega})\end{array}$ & $\mathbf{C}_{\mathbf{1}}$ & $\begin{array}{c}\mathbf{R w} \\
(\boldsymbol{\Omega})\end{array}$ & $\mathbf{C}_{\mathbf{3}}$ & $\begin{array}{c}\boldsymbol{\tau} \mathbf{(} \\
(\mathbf{m s})\end{array}$ \\
\hline Bare TiO $_{2}$ & 28 & 87 & 5.60 & 174 & 2.80 & 0.47 \\
& & & E-05 & & E-05 & \\
\hline Seeding & 23 & 305. & 1.60 & 84 & 3.27 & 0.37 \\
T- ITO & & & E-04 & & E-05 & \\
\hline 6h T-ITO & 27 & 86 & 5.60 & 145 & 4.00 & 2 \\
& & & E-05 & & E-04 & \\
\hline 12h T- & 35 & 171 & 2.60 & 84 & 5.60 & 2 \\
ITO & & & E-04 & & E-05 & \\
\hline 24h T- & 23 & 49 & 4.06 & 134 & $1.32 \mathrm{E}-$ & 20 \\
ITO & & & E-09 & & 04 & \\
\hline
\end{tabular}

According to table 3, 24h T-ITO system give the best performance among the all cells. It has low $\mathrm{Rw}$ and Rct resistance values, lower $\mathrm{Rw}$ means that, 24h T-ITO system showed the most efficient charge transfer process at dye coated $\mathrm{TiO}_{2}$ layer / treated ITO layer or dye coated $\mathrm{TiO}_{2}$ / redox electrolyte interface on this work. Lowest Rct means 
that $24 \mathrm{~h}$ T-ITO system was exhibited higher electron flow process between $\mathrm{Pt}$ counter electrolytes / redox electrolyte interfaces.

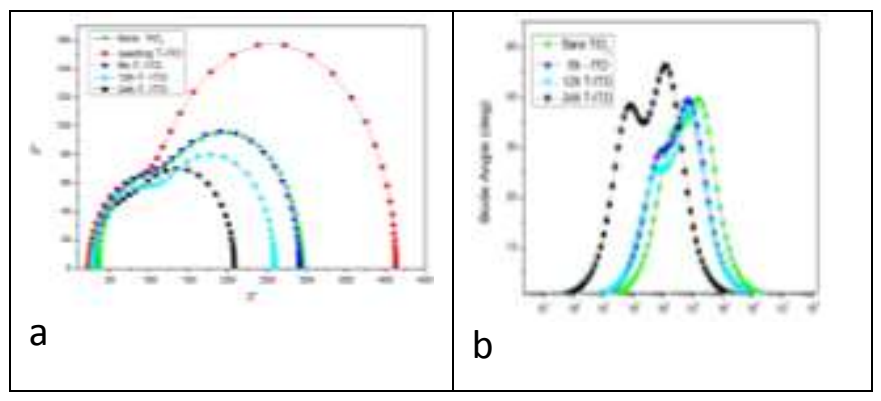

Figure 8. a. Nyquist plots of EIS data comparison of cells b. Bode plots of comparison of cells

On the bode phase plot of EIS spectra, as shown figure 10, Frequency of charge transfer process at different interfaces produced by sol gel method were shown in frequency versus theta (angle). The characteristic low frequency peaks ( $f$ max) are located $1050 \mathrm{~Hz}$ for bare $\mathrm{TiO}_{2}$ and $220 \mathrm{~Hz}$ for $6 \mathrm{~h} \mathrm{T-ITO}$ and $25 \mathrm{~Hz}$ for $24 \mathrm{~h}$ T-ITO. The most important parameter affecting the efficiency of electron life time for recombination at DSSC can be calculated from bode plot characteristic peak from $f$ max value equation of $(\tau=1 / 2 \pi f \max )$.

\section{Iv. Conclusion}

Semiconductor metal oxide nanowires (SCMONWs), favorable materials for various quantum devices which have 1 $\mathrm{D}$ interaction and huge surface-volume ratio, were synthesized by a novel technique. Indium tin oxide (ITO) is primarily used as a transparent conducting oxide for solar cells and LCD applications. The sol-gel technique can be an alternative production method for one dimensional materials. In this work, we successfully produced ITO nano powders, nanowires and films on glass substrates (TCO) using sol-gel technique. ITO nanowire treatment between the conductive transparent ITO film and $\mathrm{TiO}_{2}$ matrix improved photovoltaic efficiency. This efficiency increase due to decrease the serial resistance parts and increase the shunt resistance. Higher shunt resistance enable to higher Isc, and higher fill factor, better IPCE. And also EIS measurements said that diffusion length and recombination time increase whit increase ITO treatment time. The finally highly efficient transport and improve dye sensitized solar cell and maximum performance of Sol-gel based DSSC has been obtained by ITO NW treatment.

\section{References}

[1] Oregan, B. and M. Gratzel, A Low-Cost, High-Efficiency Solar-Cell Based on Dye-Sensitized Colloidal TiO2 Films. Nature, 1991. 353(6346): p. 737-740.

[2] Nazeeruddin, M.K., et al., Raman Characterization of Charge-Transfer Transitions in Ligand-Bridged Binuclear Polypyridyl Complexes of Ruthenium(Ii). Journal of the Chemical Society-Dalton Transactions, 1993(2): p. 323-325.
[3] Barbe, C.J., et al., Nanocrystalline titanium oxide electrodes for photovoltaic applications. Journal of the American Ceramic Society, 1997. 80(12): p. 3157-3171.

[4] Zakeeruddin, S.M., et al., Design, synthesis, and application of amphiphilic ruthenium polypyridyl photosensitizers in solar cells based on nanocrystalline $\mathrm{TiO} 2$ films. Langmuir, 2002. 18(3): p. 952-954.

[5] Nazeeruddin, M.K., et al., Investigation of sensitizer adsorption and the influence of protons on current and voltage of a dye-sensitized nanocrystalline TiO2 solar cell. Journal of Physical Chemistry B, 2003. 107(34): p. 8981-8987.

[6] Gratzel, M., Solar energy conversion by dye-sensitized photovoltaic cells. Inorganic Chemistry, 2005. 44(20): p. 6841-6851.

[7] Ito, S., et al., Fabrication of thin film dye sensitized solar cells with solar to electric power conversion efficiency over 10\%. Thin Solid Films, 2008. 516(14): p. 4613-4619.

[8] Bisht, H., et al., Comparison of spray pyrolyzed FTO, ATO and ITO coatings for flat and bent glass substrates. Thin Solid Films, 1999. 351(1-2): p. 109-114.

[9] Kovtyukhova, N.I. and T.E. Mallouk, Conductive indium-tin oxide nanowire and nanotube arrays made by electrochemically assisted deposition in template membranes: switching between wire and tube growth modes by surface chemical modification of the template. Nanoscale, 2011. 3(4): p. 1541-1552.J. Clerk Maxwell, A Treatise on Electricity and Magnetism, 3rd ed., vol. 2. Oxford: Clarendon, 1892, pp.68-73.

[10] Chopra, K.L., S. Major, and D.K. Pandya, Transparent Conductors - a Status Review. Thin Solid Films, 1983. 102(1): p. 1-46.

[11] Fabregat-Santiago, F., et al., Mott-Schottky analysis of nanoporous semiconductor electrodes in dielectric state deposited on $\mathrm{SnO} 2(\mathrm{~F})$ conducting substrates. Journal of the Electrochemical Society, 2003. 150(6): p. E293-E298.

[12] Warschkow, O., et al., Defect structures of tin-doped indium oxide. Journal of the American Ceramic Society, 2003. 86(10): p. 1700-1706.

[13] Warschkow, O., et al., Defect cluster aggregation and nonreducibility in tin-doped indium oxide. Journal of the American Ceramic Society, 2003. 86(10): p. $1707-1711$.

[14] Park, N.G., et al., Dye-sensitized TiO2 solar cells: Structural and photoelectrochemical characterization of nanocrystalline electrodes formed from the hydrolysis of TiCl4. Journal of Physical Chemistry B, 1999. 103(17): p. 3308-3314.

[15] Kundu, S. and P.K. Biswas, Synthesis of nanostructured sol-gel ITO films at different temperatures and study of their absorption and photoluminescence properties. Optical Materials, 2008. 31(2): p. 429433.

[16] Cho, H. and Y.H. Yun, Characterization of indium tin oxide (ITO) thin films prepared by a sol-gel spin coating process. Ceramics International, 2011. 37(2): p. 615-619.

[17] Law, M., et al., Nanowire dye-sensitized solar cells. Nature Materials, 2005. 4(6): p. 455-459.

[18] Yoon, J.H., et al., TiO2 nanorods as additive to $\mathrm{TiO} 2$ film for improvement in the performance of dye-sensitized solar cells. Journal of Photochemistry and Photobiology a-Chemistry, 2006. 180(1-2): p. 184188.

[19] Joanni, E., et al., Dye-sensitized solar cell architecture based on indiumtin oxide nanowires coated with titanium dioxide. Scripta Materialia, 2007. 57(3): p. 277-280.

[20] Vomiero, A., et al., Controlled growth and sensing properties of In2O3 nanowires. Crystal Growth \& Design, 2007. 7(12): p. 2500-2504.

[21] Park, J.H., et al., Wafer-Scale Growth of ITO Nanorods by Radio Frequency Magnetron Sputtering Deposition. Journal of the Electrochemical Society, 2011. 158(5): p. K131-K135.

[22] Xue, X.Y., et al., Synthesis and ethanol sensing properties of indiumdoped tin oxide nanowires. Applied Physics Letters, 2006. 88(20)..

About Author (s):

Assoc. Prof. Dr. Halil Ibrahim Yavuz
He has finished PhD on 2014 at
Department of Metallurgical and
Materials Engineering, Middle East
Technical University. He has more
than 400 Citations on his naners.

